\title{
Detection and Masking of Spoiled Food Smells by Odor Maps in the Olfactory Bulb
}

\author{
Yuji K. Takahashi, Shin Nagayama, and Kensaku Mori \\ Department of Physiology, Graduate School of Medicine, University of Tokyo, Tokyo 113-0033, Japan
}

Two major causes of spoiled food smells such as fatty, fishy off-flavors are alkylamines liberated by bacterial actions and aliphatic acids-aldehydes generated by lipid oxidation. Using the method of intrinsic signal imaging, we mapped alkylamine-responsive glomeruli to a subregion of the aliphatic acid-responsive and aldehyde-responsive cluster in the odor maps of rat olfactory bulb. Extracellular single-unit recordings from mitral-tufted cells in the subregion showed that individual cells responded to the alkylamines in addition to acids and aldehydes. Responses of mitral-tufted cells tended to last for a long period (5-88 sec) even after the cessation of the alkylamine stimulation. These results suggest that the subregion is part of the representation of the fatty, fishy odor quality. Fennel and clove, spices known to add flavor and mask the fatty, fishy odor, activated glomeruli in the surrounding clusters and suppressed the alkylamineinduced and acid-aldehyde-induced responses of mitral cells, suggesting that the odor masking is mediated, in part, by lateral inhibitory connections in the odor maps of the olfactory bulb.

Key words: olfactory bulb; odor maps; off-flavor; lateral inhibitory connections; amines; mitral cell

\section{Introduction}

The olfactory bulb $(\mathrm{OB})$ is the first center of odor information processing in the mammalian brain, and it is covered by a few thousand glomeruli. Individual glomeruli represent a single odorant receptor (OR) (Buck, 2000). Thus, the glomerular sheet of the OB forms two maps of ORs (Buck, 1996; Mori et al., 1999). Although the knowledge of odorant-evoked activity maps (odor maps) is rapidly accumulating (Uchida et al., 2000; Leon and Johnson, 2003; Xu et al., 2003; Takahashi et al., 2004), neuronal mechanisms by which odors interact at the level of odor maps in the $\mathrm{OB}$ are not well understood. A good model for the interaction is how an objectionable odor is masked by a pleasant odor.

Unpleasant off-flavor odors play a key role in detecting spoiled food and thus in avoiding the ingestion of toxins produced by food-borne micro-organisms. A sensitive marker of meat spoilage is the distinct unpleasant odor of amines that are produced by the decarboxylation of free amino acids in the fish and meat caused by to bacterial enzymes (Reineccius, 1991; Ashie et al., 1996; Silla Santos, 1996; Gram et al., 2002). For example, decarboxylation of leucine produces isopentylamine that has fatty, fishy odor, whereas that of lysine produces cadaverine with rancid, fishy odor of decaying meat (Fig. 1). Repellent nature of alkylamines was shown also in rats (Dielenberg and McGregor, 2001). Other major fatty, fishy off-flavors are the aliphatic acids and aldehydes that are generated by lipid oxidation of meat and

Received June 24, 2004; revised Aug. 30, 2004; accepted Aug. 30, 2004.

This work was supported by Grants-in-aids for Creative Scientific Research (K.M.) and Young Scientists (Y.K.T.) from Japan Society for the Promotion of Science. We thank Drs. G. M. Shepherd, C. A. Greer, and members of the Department of Physiology for the comments on this manuscript.

Correspondence should be addressed to Kensaku Mori, Department of Physiology, University of Tokyo Graduate School of Medicine, 7-3-1 Hongo, Bunkyo-ku, Tokyo 113-0033 Japan. E-mail: moriken@m.u-tokyo.ac.jp.

DOI:10.1523/JNEUROSCI.2510-04.2004

Copyright $\odot 2004$ Society for Neuroscience $\quad$ 0270-6474/04/248690-05\$15.00/0 dairy products (Hughes, 1960; Forss, 1964; Shipe et al., 1978; Badings, 1991; Mottram, 1991; Nijssen, 1991; Ashie et al., 1996; St. Angelo, 1996) (Fig. 1).

Using the method of intrinsic signal imaging (Rubin and Katz, 1999; Uchida et al., 2000; Meister and Bonhoeffer, 2001; Takahashi et al., 2004), we thus mapped the dorsal and dorsolateral parts of the glomerular sheet for alkylamine odorants that have unpleasant fatty, fishy odor, and for spice odorants that is known to mask the fatty, fishy odor. We then recorded single-unit activity from mitral cells and examined the effect of spice odorants to the alkylamine-induced responses of mitral cells. The results are consistent with the hypothesis that the spice odor maps interfere with the alkylamine odor maps, presumably through lateral inhibitory connections in the OB.

\section{Materials and Methods}

Twenty-three male Wistar rats (200-300 gm) were used in this study. All experiments were performed in accordance with the guidelines of the Physiological Society of Japan and the animal experiment committee of the University of Tokyo.

Intrinsic signal imaging and data analysis. Eleven rats were anesthetized with medetomidine $(0.5 \mathrm{mg} / \mathrm{kg}$, i.p.), ketamine $(67.5 \mathrm{mg} / \mathrm{kg}$, i.p.), and pentothal sodium $(25 \mathrm{mg} / \mathrm{kg}$, i.p.), in that order, and the skull overlying the dorsal and dorsolateral surfaces of the $\mathrm{OB}$ was removed (Takahashi et al., 2004). The exposed surface was covered with $1.5 \%$ agarose gel and glass slip.

The optical imaging device and the experimental procedures for the measurement of intrinsic signals were described in detail previously (Uchida et al., 2000). Light reflectance from the surface of the OB (705 $\mathrm{nm}$ wavelength light illumination) (Meister and Bonhoeffer, 2001) were captured using a CCD camera (CS8310; TELI, Tokyo, Japan), digitized, and stored with a Pentium PC using a frame grabber board (Pulsar; Matrox, Quebec, Canada). We imaged a $4.2 \times 3.1 \mathrm{~mm}$ region with a spatial resolution of $320 \times 240$ pixels (after $2 \times 2$ binning). For each recording trial, data were collected for $8 \mathrm{sec}$ with a frame duration of 500 


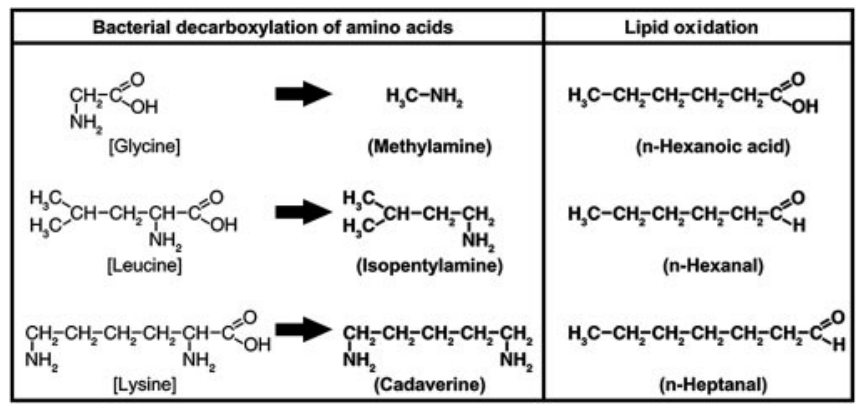

Figure 1. Two major fatty, fishy off-flavors in foods. Left column, Bacterial decarboxylation of free amino acids produces amines. Right column, 0xidative degradation of lipids produces aliphatic acids and aliphatic aldehydes.

msec ( 16 frames/trial). Odorant stimulation was applied from the beginning of the fourth to the end of the sixteenth frame. Individual odorants were tested more than four times per animal.

Images were analyzed using IDL (Research Systems, Boulder, CO) and MetaMorph (Universal Imaging, West Chester, PA) software. Images of odorant-induced responses were obtained by dividing the magnitude of signals acquired during odorant stimulation (in most cases, frames 10 16) by that acquired before stimulation (frames 1-4). A Gaussian spatial filter was used to eliminate nonspecific global darkening and highfrequency noise of the differential image (cutoff frequencies, $\sigma=$ $20.0 / \mathrm{mm}$ for high cut and $\sigma=0.2 / \mathrm{mm}$ for low cut). To analyze the odorant response specificity of individual glomeruli, hypothetical glomeruli ( $150 \mu \mathrm{m}$ in diameter) were set on the center of dark spots, and the mean pixel value was measured. Glomerular activity was calculated by subtracting the prestimulus baseline value. The intensity of glomerular activity was classified into four levels: $0.040-0.055 \%$ change in light intensity is weak (the smallest circle in Fig. $3 A$ ), $0.055-0.070 \%$ is modest (a small circle), $0.070-0.085 \%$ is strong (a large circle), and $>0.085 \%$ is very strong (the largest circle).

Extracellular single-unit recording. Twelve rats were anesthetized with urethane (1.2 gm $/ \mathrm{kg}$, i.p.). After exposure of the dorsal surface of the OB, a recording glass micropipette $(10-15 \mathrm{M} \Omega \mathrm{DC}$ resistance; filled with $4 \mathrm{M}$ $\mathrm{NaCl}$ ) was inserted into the dorsomedial region for the extracellular single-unit recording. A stainless concentric electrode was inserted in the lateral olfactory tract (LOT) for electrical stimulation (100 $\mu$ sec in duration). Respiratory rhythms were detected using a strain gauge attached around the animal's chest (652-T; Nihon Kohden, Tokyo, Japan). The recorded signals were stored in the computer via analog-to-digital converter with spike2 software (Cambridge Electronic Design, Cambridge, UK).

The magnitude of the odorant-evoked response was calculated by subtracting the number of spikes that occurred during 2 sec before the stimulus onset from the number of spikes that occurred during $2 \mathrm{sec}$ after the stimulus onset. Each odorant was tested more than three times per unit. Then the averaged magnitude of the odorant-evoked response and their SEM were calculated. For the estimation of the fluctuation of spontaneous discharges, the number of spikes that occurred from 5 to $3 \mathrm{sec}$ and 3 to $1 \mathrm{sec}$ before stimulus onset was counted. The magnitude of fluctuation of spike frequency was calculated by subtracting the former from the latter. We averaged the spontaneous fluctuations and determined the SD of the spontaneous fluctuation for each cell. When odorant responses were $>2 \mathrm{SD}$, we considered them significant.

Odorants and odorant stimulation. Odorants were purchased from Sigma (St. Louis, MO), Tokyo Kasei Organic Chemicals (Tokyo, Japan), and Nacalai Tesque (Kyoto, Japan) and yielded by T. Hasegawa Company, Ltd. (Tokyo, Japan). Aliphatic amines, aliphatic acids, and aliphatic aldehydes were diluted to 1:50 (v/v) with the odorless mineral oil. Odorant stimulation was performed by placing the opening of an odorant-containing test tube at a distance of $10 \mathrm{~mm}$ from the animal's nostril.

To check the concentration of tested odorants, we sampled the five representative odorants at the tip of the animal's nostril that was $10 \mathrm{~mm}$

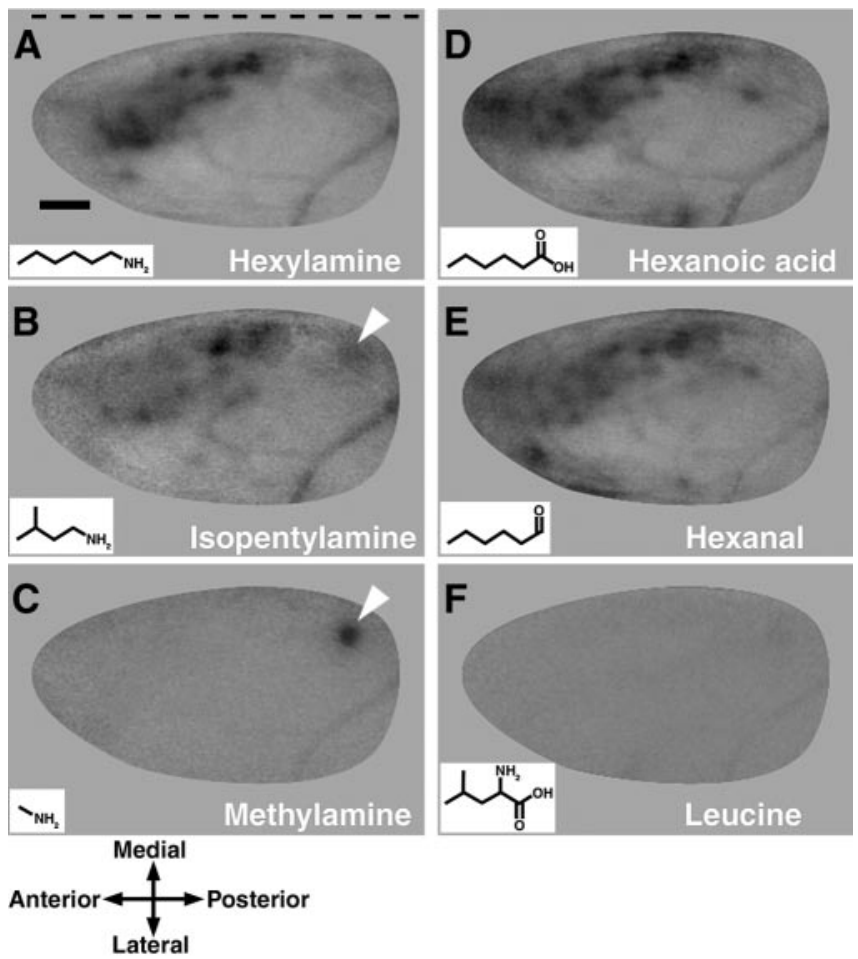

Figure 2. Alkylamines activate a large cluster of glomeruli in the anteromedial part and a small cluster of glomeruli in the posteromedial part of the dorsal OB. A-F, Optical images of intrinsic signals in response to hexylamine $(A)$, isopentylamine $(B)$, methylamine $(C$, hexanoic $\operatorname{acid}(D)$, hexanal $(E)$, and leucine $(D)$. The molecular structure of each odorant is shown in the inset. Dashed line in $A$ indicates the estimated position of midline of the rat brain. White arrowheads in $B$ and $C$ indicate the position of amine-responsive glomeruli in the posteromedial cluster. Scale bar, $500 \mu \mathrm{m}$.

distant from the opening of the odorant-containing test tube. Gas chromatographic analysis showed the following concentrations: hexanoic acid, $0.13 \pm 0.06 \mathrm{ppm}$ (mean $\pm \mathrm{SD}$ ); hexanal, $0.63 \pm 0.15 \mathrm{ppm}$; hexylamine, $1.33 \pm 0.25 \mathrm{ppm}$; trans-anethole, $0.13 \pm 0.06 \mathrm{ppm}$; and eugenol, $0.17 \pm 0.06 \mathrm{ppm}$.

\section{Results}

\section{Alkylamine-responsive glomerular clusters}

A homologous series of alkylamines $\left(\mathrm{C} 4-\mathrm{C} 8 \mathrm{NH}_{2}\right)$ activated a large cluster of glomeruli in the anteromedial part and a small cluster of glomeruli in the posteromedial part of the dorsal surface of the $\mathrm{OB}$ (Fig. 2A,B). Methylamine (Fig. 2C) and trimethylamine, both of which having an ammonia-like note, selectively activated a few glomeruli at the posteromedial cluster (white arrowhead).

Because the positions of amine-responsive glomeruli extensively overlapped with those of the aliphatic acid-responsive and aliphatic aldehyde-responsive glomeruli (Fig. 2D,E) (Uchida et al., 2000; Takahashi et al., 2004), we examined in detail with the optical imaging method whether individual amine-responsive glomeruli respond also to aliphatic acids and aldehydes. Figure $3 A$ shows the odorant response specificity of individual glomeruli (numbered from 1 to 53 ) in a rat $\mathrm{OB}$ to a systematic panel of odorants containing homologous series of aliphatic amines (orange), acids (red), and aldehydes (blue). The positions of individual glomeruli listed in Figure $3 A$ are shown by circles with glomerulus number in the diagram of the dorsal surface of the $\mathrm{OB}$ in Figure $3 B$. Figure $3 C$ shows the results of the mapping in the $\mathrm{OB}$ of another rat. In all seven rats examined, the alkylamineresponsive glomeruli were activated also by aliphatic acids and 
aldehydes, and the large anteromedial cluster of alkylamine-responsive glomeruli (surrounded by a green line with an arrowhead) was always located within the aliphatic acid-aldehyde-responsive cluster (surrounded by a red line with an arrow) (Fig. 3B,C). In addition, a small cluster of glomeruli (Fig. 3B,C, surrounded by a green line with an asterisk) that responded to amines with short carbon chain, cadaverine, and trimethylamine was consistently observed at the posteromedial part, which was caudally adjacent to the aliphatic acid-responsive and aldehyderesponsive cluster (Fig. 3A-C).

\section{Individual mitral-tufted cells respond to three structurally different classes of odorants}

Individual mitral-tufted cells in the $\mathrm{OB}$ are connected by a single primary dendrite to a single glomerulus and receive olfactory axon input within the glomerulus (Shepherd and Greer, 1998). If a single glomerulus is activated by the amines, aldehydes, and acids, mitral-tufted cells belonging to the glomerulus would respond to all three structurally different classes of odorants. We examined this possibility by recording the single-unit activity from mitral-tufted cells in the anteromedial alkylamine-responsive cluster. As shown in Figure $3 D$, individual mitral-tufted cells in the cluster responded with increased spike discharges to a subset of aliphatic amines, a subset of aliphatic aldehydes, and a subset of aliphatic acids. We noted that, in many mitral-tufted cells ( 32 of $67 \mathrm{U}$ ), responses to alkylamines lasted for a long period (5-88 sec; mean, $23 \mathrm{sec} ; n=32$ ) even after cessation of the odor stimulation (Fig. $3 E$ ).

Because amino acids have both a carboxyl group and an amino group in their molecular structure (Fig. 1) and can activate ORs in fish (Friedrich and Korsching, 1997), we examined whether the glomeruli that respond to both aliphatic acids with a carboxyl group and amines with an amino group respond to amino acids. Optical imaging from the dorsal $\mathrm{OB}$ showed that the amine-responsive and aliphatic acidresponsive glomeruli did not respond to glycine, alanine, valine, leucine, or isoleucine (Figs. $2 \mathrm{~F}, 3 \mathrm{~A}$ ). Thus, the glomeruli in the anteromedial cluster do not detect amino acids, but selectively detect their degraded compounds: amines, aldehydes, and acids.

\section{Masking of fatty, fishy off-flavor}

In cooking, a variety of spices are commonly used to add flavor and reduce any unpleasant fatty, fishy off-flavor. Fennel, for example, is known to mask the off-flavor and is called "the fish herb." Clove also is known to reduce the fatty, fishy off-flavor of meat and fish. We used the optical imaging method to map the
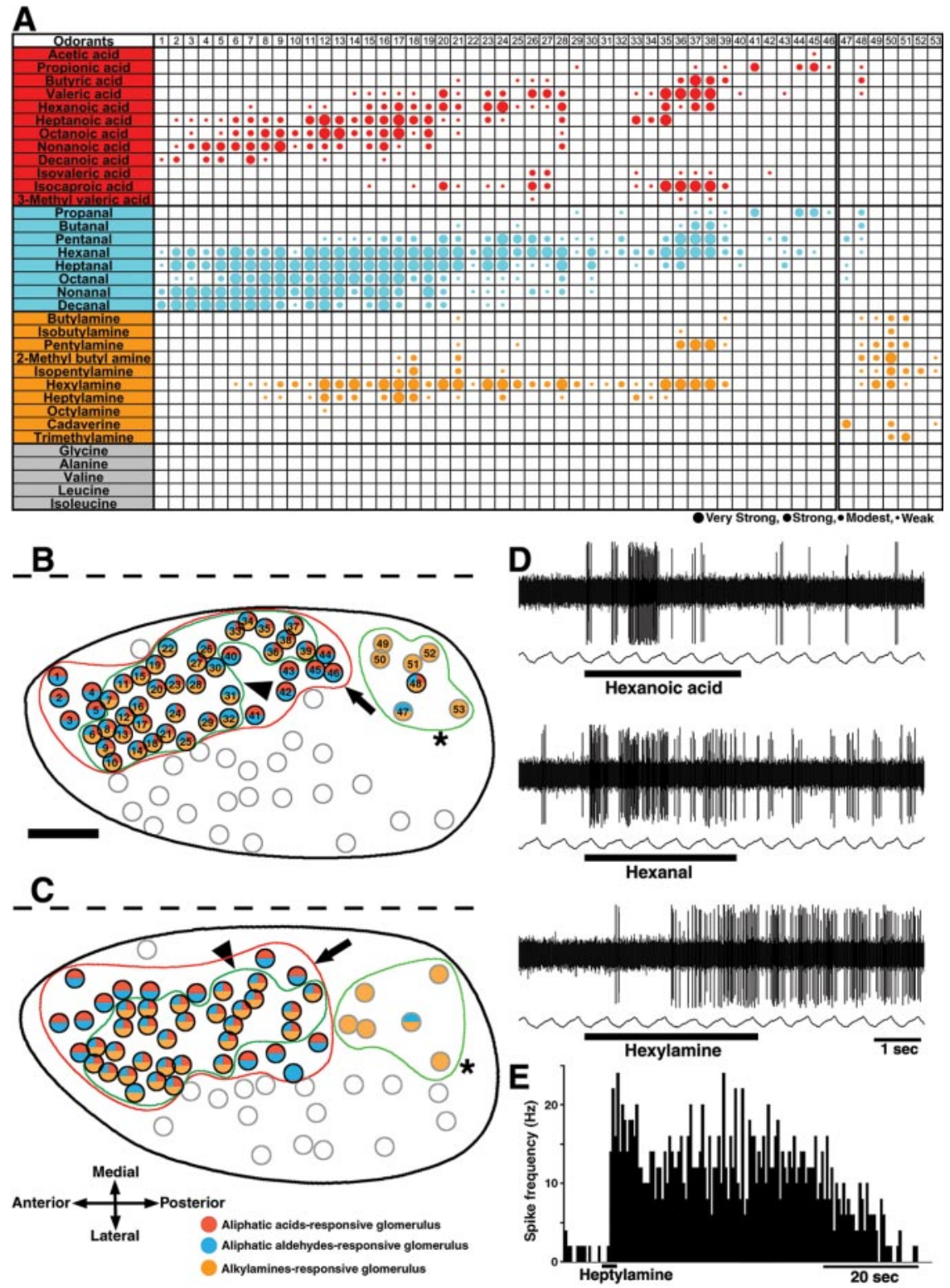

Figure 3. Individual glomeruli and mitral-tufted cells in the anteromedial cluster respond to three structurally different classes of odorants. $A$, The odorant-response specificity of glomeruli in the anteromedial cluster $(1-46$ in $B)$ and in the posteromedial cluster (47-53 in $B$ ). The left column indicates the stimulus odorants. Top row indicates glomerular number. The glomerular number corresponds to that shown in $B$. Responses were classified into four types: very strong (the largest circle), strong (a large circle), modest (a small circle), and weak (the smallest circle). Open box indicates no response. $B$, Spatial arrangement of glomeruli listed in $A$ on a dorsal surface of the $O B$ of a rat. The odorant response specificity of each glomerulus is shown in $A$. Red, blue, and orange indicate aliphatic acid-responsive, aliphatic aldehyde-responsive, and amine-responsive glomeruli, respectively. C, Spatial arrangement of amine-responsive, acid-responsive, and aldehyde-responsive glomeruli in the dorsal surface of another rat $O B$. Dashed lines in $B$ and C indicate the estimated position of the midline. Scale bar, $500 \mu \mathrm{m}$. D, Odorant-evoked spike responses of a mitral cell to hexanoic acid, hexanal, and hexylamine. E, Spike-frequency histogram (1 bin is $500 \mathrm{msec}$ ) of the responses of a mitral cell to heptylamine stimulation.

glomeruli that responded to the odors of fennel oil or clove oil in the dorsal and dorsolateral surfaces of the $\mathrm{OB}$, and we found that the spices activated clusters of glomeruli that were located near the anteromedial alkylamine-responsive cluster. Fennel and its major component trans-anethole activated clusters of glomeruli that were located lateral to the alkylamine-responsive cluster (Fig. 4C,D, $G$ ). The clusters of glomeruli that responded to clove oil and its major component eugenol overlapped in part with the fennel-responsive clusters and surrounded the amine-responsive cluster (Fig. 4E-G). 

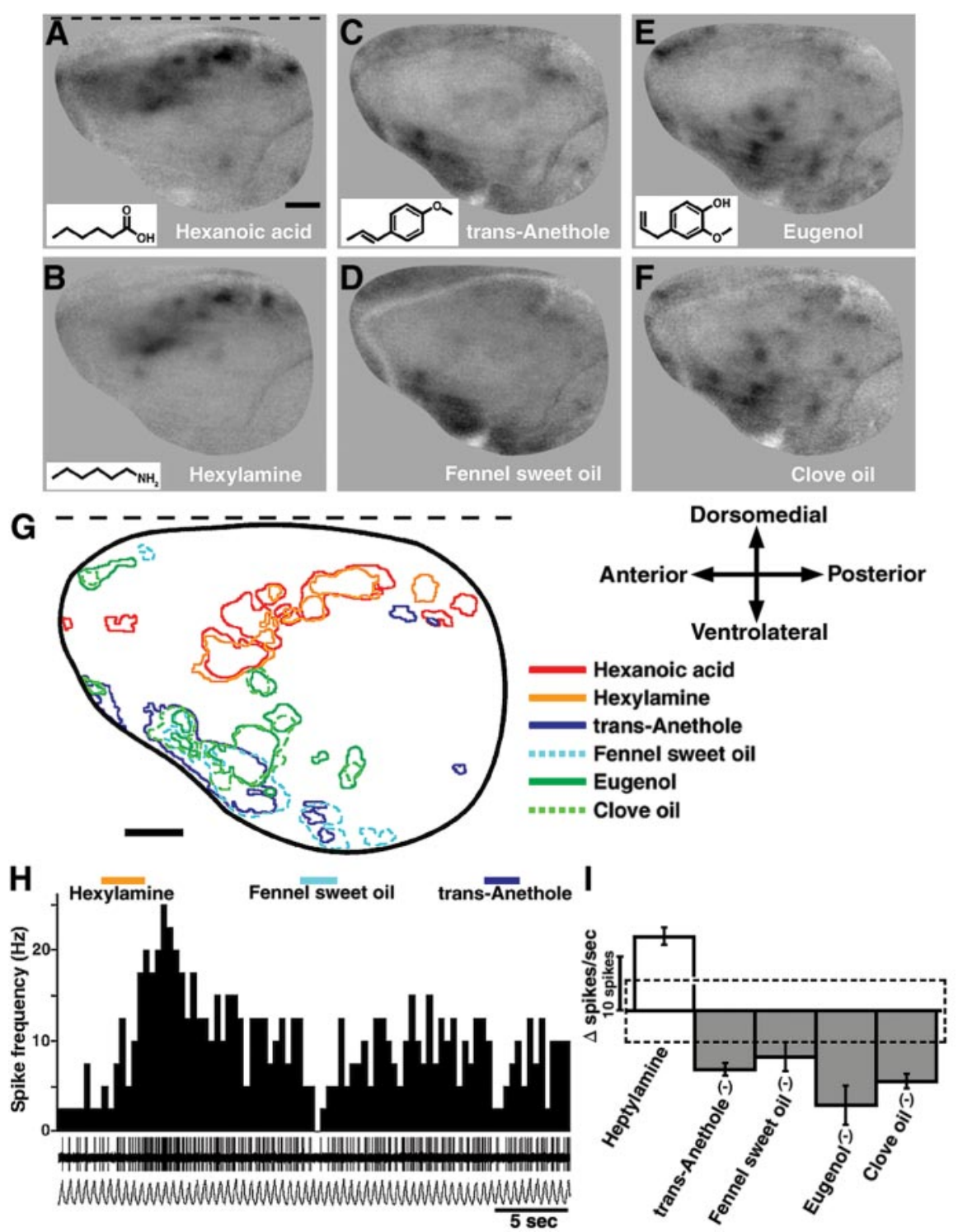

Figure 4. Odors of spices activate neighboring clusters and suppress spike activity of alkylamine-responsive mitral cells. $A-F$, Glomerular responses elicited by hexanoic acid $(A)$, hexylamine $(B)$, trans-anethole $(C$, fennel sweet oil $(D)$, eugenol $(E)$, and clove oil ( $F$ ). G, Superimposed map of optically recorded responses to hexanoic acid (red line), hexylamine (orange line), transanethole (blue line), fennel sweet oil (pale blue dashed line), eugenol (green line), and clove oil (green dashed line). Dashed black lines in $A$ and $G$ indicate the estimated position of midline. Scale bars: $A$ (for $A-F), G, 500 \mu \mathrm{m} . H, 0$ dorant-evoked spike discharges of a mitral cell in response to hexylamine, fennel sweet oil, and trans-anethole. Top row shows the spike-frequency histogram (1 bin is $400 \mathrm{msec}$ ) of the mitral cell response. Odorant stimulation was indicated by color bars. Middle trace shows single-unit spike discharges, and the bottom trace is the monitor of the respiratory rhythm (upward deflection is inhalation). I, Response properties of a mitral cell to heptylamine, trans-anethole, fennel sweet oil, eugenol, and clove oil. $y$-axis indicates the increase (open bar) or decrease (filled bar) of the spike discharge rate during odorant-stimulation in comparison with that during prestimulation period. Dotted line indicates the 2 SD of fluctuation of spontaneous spike discharges. Suppressive responses $>2$ SD levels are shown by $(-)$.

Mitral cells extend their secondary dendrites tangentially for a long distance and receive lateral inhibition via local interneurons connected to mitral cells in the neighboring clusters (Aungst et al., 2003; Nagayama et al., 2004). This suggested the hypothesis that the alkylamine-induced responses of mitral cell in the anteromedial cluster might be suppressed by activation of mitral cells in the neighboring fennel-responsive and clove-responsive clusters. To examine this possibility, we recorded single-unit activity from mitral cells in the alkylamine-responsive and aldehyde-acid-responsive anteromedial cluster and examined the responses of the mitral cells to fennel sweet oil, trans- anethole, clove oil, and eugenol. The mitral cell in Figure $4 \mathrm{H}$ responded with prolonged spike discharges to hexylamine. The spike discharges were temporarily suppressed when fennel sweet oil or its major component trans-anethole was applied to the nose. Figure 4I shows the responses of another mitral cell to the spices and their major components. This cell was activated by heptylamine, and in addition was strongly suppressed by trans-anethole, fennel sweet oil, eugenol, and clove oil.

In 14 mitral cells of 33 cells examined, alkylamine-induced responses were clearly suppressed by at least one of the two spices and their major components. These results suggest that fennel and clove odors activate glomeruli in the neighboring clusters and then suppress the activity of mitral cells in the amine-responsive and aldehyde-acid-responsive cluster via the lateral inhibitory connections in the local neuronal circuit of the OB.

\section{Discussion}

In the present study, we showed that alkylamine activated a large cluster of glomeruli in the anteromedial part and a small cluster of glomeruli in the posteromedial part of the dorsal OB. The alkylamineresponsive glomeruli in the anteromedial cluster responded to aldehydes with medium-to-long carbon chains (mainly C5-C10 CHO), and especially strongly to hexanal and heptanal. The odors of hexanal and heptanal contain a fatty, fishy note, and they are major components of the fatty, tallowy, fishy off-flavor associated with oxidative degradation of lipids in meats and seafoods (Mottram et al., 1982; St. Angelo et al., 1987; Josephson, 1991; Nijssen, 1991; Refsgaard et al., 1999). cis4-heptenal, for example, has been recognized for years to be responsible for the fishy off-flavor of cold-stored cod and butter (McGill et al., 1974; Josephson, 1991). The alkylamine-responsive glomeruli were activated also by aliphatic acids with medium-to-long carbon chains (C5-C10 $\mathrm{COOH}$ ), including hexanoic acid and heptanoic acid. These acids also have rancid, fatty, fishy notes. Extracellular single-unit recording study showed that individual mitral-tufted cells in the anteromedial cluster responded not only to aliphatic acids and aldehydes but also to alkylamines. Thus, individual glomeruli and individual mitral-tufted cells in the anteromedial cluster responded to the three structurally different classes of odorants that have different odors but have a fatty, fishy note in common. These results suggest that the anteromedial amine-responsive cluster of glomeruli participate in the representation of the fatty, fishy odor quality and corroborate the hypothesis that glomerular clusters in the OB may participate in the topographic representation of odor quality (Uchida et al., 
2000; Takahashi et al., 2004). Interestingly, many mitral-tufted cells showed prolonged afterdischarges even after the cessation of the alkylamine stimulation (Fig. 3E). Besides the anteromedial and posteromedial clusters in the dorsal OB, alkylamines activated also a cluster of glomeruli in the lateral surface of the $\mathrm{OB}(\mathrm{K}$. M. Igarashi and K. Mori, unpublished data). This suggests that a specific combination of several clusters in the glomerular map handles information about alkylamine odorants.

Because fennel and clove are commonly used to mask fatty, fishy off-flavor in meat and fish, we examined whether odors of the spices suppress the activity of alkylamine-responsive mitral cells. Extracellular single-unit recordings in the anteromedial cluster showed that the activities of some alkylamine-responsive mitral cells were suppressed by the odors of the spices and their major components (Fig. 4H,I). These results indicate that the lateral inhibitory connections in the odor maps participate in the spices' masking of the fatty, fishy off-flavor, although this does not deny the possibility that the masking is mediated also at the level of olfactory sensory neurons or at the levels of higher olfactory centers, including the olfactory cortex. We previously reported that aliphatic acid-responsive and aldehyde-responsive mitral cells in the anteromedial cluster were inhibited by specific odorants that were effective in activating glomeruli in the surrounding clusters (Nagayama et al., 2004). This suggests that these odorants besides the two spice odorants can participate to a certain degree in the masking of the fatty, fishy off-flavor. However, the range of odorants that interfere with the alkylamine responses of mitral cells remains to be determined.

It is likely that there are also alkylamine-responsive clusters and spice odorant-responsive clusters in other parts of the $\mathrm{OB}$, and that together they constitute the global patterns that interact to produce the behavioral results of repellant and attractive odors and the masking between them. Further recordings of alkylamine-induced responses from mitral-tufted cells in the clusters other than the anteromedial cluster are necessary to examine whether odors of the spices suppress the alkylamine-induced activity.

The glomerular clusters with specific odorant response selectivity are stereotypically and systematically arranged in the odor maps of the rat OB (Uchida et al., 2000; Leon and Johnson, 2003; Xu et al., 2003; Takahashi et al., 2004). The spatial arrangement of the glomerular clusters and intensive interactions among mitral cells in the neighboring clusters may thus be important determinants for the mechanisms of mitral cell responses to the complex mixture of odorants (Nagayama et al., 2004). Given the parallels between humans and rats in the detection and masking of the fatty, fishy off-flavor, we speculate that the spatial organization of odor maps in the OB is basically similar between the two omnivorous mammals. If so, the manner of human perception of and emotional reaction to complex mixtures of odorants that occur in foods and beverages and in the natural environment may depend critically on the spatial organization of the odor maps in the OB. Indeed, odor masking of a particular pair of odorants, which was known in human psychophysical studies, is also observed in behavioral study of rat (Laing et al., 1989). Detailed knowledge of the odor maps in the rodent and human OB thus would provide an important basis for the science of foods and cooking (Shepherd, 2003).

\section{References}

Ashie IN, Smith JP, Simpson BK (1996) Spoilage and shelf-life extension of fresh fish and shellfish. Crit Rev Food Sci Nutr 36:87-121.

Aungst JL, Heyward PM, Puche AC, Karnup SV, Hayar A, Szabo G, Shipley MT (2003) Centre-surround inhibition among olfactory bulb glomeruli. Nature 426:623-629.
Badings HT (1991) Milk. In: Volatile compounds in foods and beverages (Maarse H, ed), pp 91-106. New York: Dekker.

Buck LB (1996) Information coding in the vertebrate olfactory system. Annu Rev Neurosci 19:517-544.

Buck LB (2000) The molecular architecture of odor and pheromone sensing in mammals. Cell 100:611-618.

Dielenberg RA, McGregor IS (2001) Defensive behavior in rats towards predatory odors: a review. Neurosci Biobehav Rev 25:597-609.

Forss DA (1964) Fishy flavor in dairy products. J Dairy Sci 47:245-250.

Friedrich RW, Korsching SI (1997) Combinatorial and chemotopic odorant coding in the zebrafish olfactory bulb visualized by optical imaging. Neuron 18:737-752.

Gram L, Ravn L, Rasch M, Bruhn JB, Christensen AB, Givskov M (2002) Food spoilage-interactions between food spoilage bacteria. Int J Food Microbiol 78:79-97.

Hughes RB (1960) Chemical studies on the herring (Clupea harengus). III. The lower fatty acids. J Sci Food Agric 11:47-53.

Josephson DB (1991) Seafood. In: Volatile compounds in foods and beverages (Maarse H, ed), pp 179-202. New York: Dekker.

Laing DG, Panhuber H, Slotnick BM (1989) Odor masking in the rat. Physiol Behav 45:689-694.

Leon M, Johnson BA (2003) Olfactory coding in the mammalian olfactory bulb. Brain Res Brain Res Rev 42:23-32.

McGill AS, Hardy R, Burt JR (1974) Hept-cis-4-enal and its contribution to the off-flavour in cold stored cod. J Sci Food Agric 25:1477-1489.

Meister M, Bonhoeffer T (2001) Tuning and topography in an odor map on the rat olfactory bulb. J Neurosci 21:1351-1360.

Mori K, Nagao H, Yoshihara Y (1999) The olfactory bulb: coding and processing of odor molecule information. Science 286:711-715.

Mottram DS (1991) Meat. In: Volatile compounds in foods and beverages (Maarse H, ed), pp 107-202. New York: Dekker.

Mottram DS, Edwards RA, MacFie HJH (1982) A comparison of the flavour volatiles from cooked beef and pork meat systems. J Sci Food Agric 33:934-944.

Nagayama S, Takahashi YK, Yoshihara Y, Mori K (2004) Mitral and tufted cells differ in the decoding manner of odor maps in the rat olfactory bulb. J Neurophysiol 91:2532-2540.

Nijssen B (1991) Off-flavors. In: Volatile compounds in foods and beverages (Maarse H, ed), pp 689-736. New York: Dekker.

Refsgaard HH, Haahr AM, Jensen B (1999) Isolation and quantification of volatiles in fish by dynamic headspace sampling and mass spectrometry. J Agric Food Chem 47:1114-1118.

Reineccius G (1991) Off-flavors in foods. Crit Rev Food Sci Nutr 29:381-402.

Rubin BD, Katz LC (1999) Optical imaging of odorant representations in the mammalian olfactory bulb. Neuron 23:499-511.

Shepherd GM (2003) Implications of recent research on olfaction for the neural basis of flavor in humans: challenges and opportunities. In: Handbook of flavor characterization: sensory, chemical, and physiological techniques (food science and technology, 131) (Deibler KD, Delwiche J, eds), pp 93-104. New York: Dekker.

Shepherd GM, Greer CA (1998) Olfactory bulb. In: The synaptic organization of the brain, Ed 4 (Shepherd GM, ed), pp 159-203. New York: Oxford UP.

Shipe WF, Bassette R, Deane DD, Dunkley WL, Hammond EG, Harper WJ, Kleyn DH, Morgan ME, Nelson JH, Scanlan RA (1978) Off flavors of milk: nomenclature, standards, and bibliography. J Dairy Sci 61:855-869.

Silla Santos MH (1996) Biogenic amines: their importance in foods. Int J Food Microbiol 29:213-231.

St. Angelo AJ (1996) Lipid oxidation on foods. Crit Rev Food Sci Nutr 36:175-224.

St. Angelo AJ, Vercellotti JR, Legendre MG, Vinnett CH, Kuan JW, James C, Dupuy HP (1987) Chemical and instrumental analyses of warmed-over flavor in beef. J Food Sci 52:1163-1168.

Takahashi YK, Kurosaki M, Hirono S, Mori K (2004) Topographic representation of odorant molecular features in the rat olfactory bulb. J Neurophysiol 92:2413-2427.

Uchida N, Takahashi YK, Tanifuji M, Mori K (2000) Odor maps in the mammalian olfactory bulb: domain organization and odorant structural features. Nat Neurosci 3:1035-1043.

Xu F, Liu N, Kida I, Rothman DL, Hyder F, Shepherd GM (2003) Odor maps of aldehydes and esters revealed by functional MRI in the glomerular layer of the mouse olfactory bulb. Proc Natl Acad Sci USA 100: $11029-11034$. 